\title{
Alkaline Fractionation and Subsequent Production of Nano-Structured Silica and Cellulose Nano-Fibrils for the Comprehensive Utilization of Rice Husk
}

\author{
Hyun Jin Jung ${ }^{1,2}$, Hyun Kwak ${ }^{2}$, Jinyoung Chun ${ }^{3}$ and Kyeong Keun $\mathrm{Oh}^{1,2, * \mathbb{C}}$ \\ 1 Department of Chemical Engineering, Dankook University, Yongin, Gyeonggi-do 16890, Korea; \\ hjjung@sugaren.co.kr \\ 2 R\&D Center, SugarEn Co., Ltd., Yongin, Gyeonggi-do 16890, Korea; hkwak@sugaren.co.kr \\ 3 Korea Institute of Ceramic Engineering and Technology (KICET), Jinju, Gyeongsangnam-do 52851, Korea; \\ jchun@kicet.re.kr \\ * Correspondence: kkoh@dankook.ac.kr; Tel.: +82-31-8005-3549
}

Citation: Jung, H.J.; Kwak, H.; Chun, J.; Oh, K.K. Alkaline Fractionation and Subsequent Production of

Nano-Structured Silica and Cellulose Nano-Fibrils for the Comprehensive Utilization of Rice Husk. Sustainability 2021, 13, 1951. https://doi.org/ $10.3390 /$ su13041951

Academic Editor: Dirk Enke

Received: 3 December 2020

Accepted: 8 February 2021

Published: 11 February 2021

Publisher's Note: MDPI stays neutral with regard to jurisdictional claims in published maps and institutional affiliations.

Copyright: (c) 2021 by the authors. Licensee MDPI, Basel, Switzerland. This article is an open access article distributed under the terms and conditions of the Creative Commons Attribution (CC BY) license (https:// creativecommons.org/licenses/by/ $4.0 /)$.

\begin{abstract}
The parameters of the alkaline fractionation process were investigated and optimized using a statistical analysis method to simultaneously remove hemicellulose and ash from rice husk (RH) concomitantly. After the alkaline fractionation process, the residual solid contained high cellulose, and the recovery yield of hemicellulose was enhanced in the fractionated liquid hydrolyzate. The hemicellulosic sugar recovery yield (71.6\%), de-ashing yield (>99\%), and lignin removal (>80\%) were obtained at the reaction conditions of $150{ }^{\circ} \mathrm{C}$ of temperature, $40 \mathrm{~min}$ of reaction time, and $6 \%$ $(w / v)$ of $\mathrm{NaOH}$ concentration. Subsequently, nano-structured silica was synthesized using black liquor obtained as a by-product of this fractionation process. For the production of nano-structured silica, it was observed that the $\mathrm{pH}$ of a black liquor and the heat treatment temperature significantly influenced the textural properties of silica product. In addition, the two-stage bleaching of solid residue followed by colloid milling for the production of high value-added CNF with was attempted. As a result, in addition to $119 \mathrm{~g}$ of fermentable sugar, $143 \mathrm{~g}$ of high-purity ( $>98 \%)$ silica with a surface area of $328 \mathrm{~m}^{2} \mathrm{~g}^{-1}$ and $273.1 \mathrm{~g}$ of high-functional CNF with cellulose content of $80.1 \%$ were simultaneously obtained from $1000 \mathrm{~g}$ of $\mathrm{RH}$.
\end{abstract}

Keywords: biorefinery; multi-objectives RSM; nano-silica; de-ashing; cellulose crystals

\section{Introduction}

In response to growing concerns about environmental pollution caused by excessive consumption of fossil fuels, many researchers are pursuing alternative bio-based resources that can be applied to related industries. Among various candidates, lignocellulosic biomass, including agro-industrial and agricultural wastes, has attracted an intensive interest in the production of biofuels and chemicals, which are desirable alternatives to conventional petroleum-based fuels and chemicals. The biodegradability, reproducibility, and abundance of lignocellulosic biomass make it a promising resource for the production of these bio-based products [1]. Thus, lignocellulosic biomass has emerged as a potential renewable resource due to its annual reproducibility and abundance.

To secure the economic feasibility of biorefinery, a biorefinery system for producing value-added chemicals, i.e., an integrated biomass conversion process, must be conceived. To operate the biorefining process efficiently, each component of biomass must be separated sequentially by an effective and technically feasible fractionation process [2,3]. Rice is one of the most cultivated crops in the world; in 2018, approximately 661 million tons of rice were cultivated worldwide. Therefore, rice husk $(\mathrm{RH})$ is a major side product of the agricultural industry, because its weight accounts for approximately $20 \mathrm{wt} . \%$ of rice plant [4]. Since $\mathrm{RH}$ is obtained through the milling process, it has already been processed first, suitable 
for further chemical and physical treatment without any additional drying or grinding process. In Korea, domestic RPCs (rice process complexes) perform rice milling according to demand, so they can produce relatively uniform amounts of RH throughout the year [5]. Nevertheless, most of the current RH is either burned in the field or used as compost in the soil as a quick and easy disposal method [6]. However, these methods of disposal are a major source of air pollution from smoke and greenhouse gases. In particular, $\mathrm{RH}$ combustion is evaluated as socially unacceptable due to the widespread air pollution increasing organic carbon emission [7]. The inclusion of some $\mathrm{RH}$ in the soil is a common management practice to improve soil fertility [8] and to prevent the harmful effects of long-term agricultural activities [9]. However, composting of RH increases emission of methane gas, one of the major greenhouse gases [10].

There has been a considerable amount of research on the use of $\mathrm{RH}$ over the past few years. Since RH is composed of a large amount of lignocellulose and ash, numerous studies have been focused on the preparation of high value-added products such as lignin, silica, and fermentable sugar to utilize $\mathrm{RH}$ as a raw material in various bio-based industries [11-13]. For examples, hemicellulose is hydrolyzed into sugars (mainly xylose) and substituted sugar oligomers [14,15], cellulose is hydrolyzed into glucose and then fermented into ethanol $[16,17]$, and ash is used for preparation of pure fine silica [18,19]. In particular, the silicified surface of RH acts as a protective barrier, specifically conferring an outstanding recalcitrance toward biological threats, which leads to inefficient hydrolysis of cellulose and hemicellulose. Accordingly, the release of fermentable sugar from the tightly woven structure of cell wall is considered a prerequisite to obtaining bio-based products through the biological conversion process [20].

Interestingly, silica $\left(\mathrm{SiO}_{2}\right)$ accounts for $80-95 \%$ of the inorganic components in $\mathrm{RH}[21,22]$. Therefore, after extraction of the cellulosic components through fractionation, silica-based products can be obtained from the byproduct liquor (black liquor). The morphology and purity of the silica products can be changed through post-treatment of black liquor. Therefore, the development of an appropriate post-treatment process with optimized conditions can lead to the production of high purity/grade nano-structured silica from black liquor. Currently, a large amount of silica is widely used in various industries. In particular, nano-structured silica with unique characteristics is required for various modern applications such as biosensors [23], drug delivery systems [24], wastewater treatment [25], and superhydrophobic coatings [26], which are expected to grow rapidly [27]. Accordingly, the facile preparation of high-purity nano-structured silica from $\mathrm{RH}$ is an important research theme, because the production of high value-added silica from a low-cost raw material and the effective treatment of waste biomass can be achieved simultaneously. Fernandes et al. [28] suggested that the effective production of silica from RH is generally based on a combination of appropriate chemical and heat treatment conditions.

On the other hand, due to the specific chemical and physical properties of biomassderived cellulose, the interest in their research and development is rapidly increasing. However, cellulose is still limited in its use in industrial applications due to its unique properties such as water insolubility, hygroscopicity, and non-melting properties. Nevertheless, until recently, many researchers have found that when biomass cellulose is subjected to mechanical shear or controlled hydrolysis, elongated fibrils or defect-free rod-shaped crystal particles are obtained in the nanoscale range, and that they were named nano-cellulose [29]. Nano-cellulose has many advantages such as high mechanical strength, large aspect ratio, low density, high specific surface area, and excellent biocompatibility. In particular, by modifying the surface chemical properties of nano-cellulose through various development strategies, it is possible to change the properties to meet various industrial needs [30]. Thus, nano-cellulose can be a versatile source of various products in the form of commercial cellulose derivatives through chemical modification [31]. Typically, nano-cellulose is divided into two main types. That is, it can be broadly classified into cellulose nanocrystals (CNC) obtained from acid treatment and cellulose nano-fibrils (CNF) mainly produced by mechanical disintegration. CNF has become a more attractive material 
for industrial use, and as CNF can be produced on a commercial scale, this material has become readily available through the market. Thus, CNF has received more attention in industrial applications. In relation to CNF from lignocellulosic biomass, many R\&Ds have been proposed to develop and optimize production technologies or to impart new properties to materials of special and high industrial value [32-36].

In our previous work to effectively utilize the lignocellulosic biomass, glucose and xylose were produced as the raw materials for production of biofuel by hydrolyzing cellulose and hemicellulose through optimized fractionation process. In addition, ball milling combined in the presence of chemical catalyst has been shown to be an effective fractionation method because of increasing mixing effectiveness, reducing particle size and increasing larger accessible surface area, resulting in significantly improved fractionation of herbaceous biomass [37-39]. However, unavoidable substantial byproduct formation after recovery of the fermentable sugars incurs additional costs for the associated waste treatment, which can increase the production cost. Therefore, it is speculated that a conversion strategy for the utilizing by-products produced in the fractionation process is required [40].

In the current study, alkaline fractionation of RH has been attempted to selectively separate the components from RH. The objective of this study was to recover hemicellulosic sugar and ash (mainly silica), while retaining most of the cellulosic component in the solid residue. Numerous studies, however, have been conducted to produce bioethanol using xylose in liquid phase and cellulose in solid phase. Therefore, the focus of the research is on the multi-purpose optimization of the alkali fractionation process, which can simultaneously meet the recovery of hemicellulosic sugar (mainly xylose) and the de-ashing yield from RH. In addition, the studies were conducted to secure bio-based materials from rice husk other than biofuels. After fractionation of the $\mathrm{RH}$, with the aim of producing high value-added bio-based materials from fractionation residues, new synthetic methods for producing high-purity nano-silica from liquid residues were investigated, and a series of experiments were conducted to produce CNF from solid residues.

\section{Materials and Methods}

\subsection{Feedstock Preparation}

$\mathrm{RH}$ was obtained as a by-product from local rice process complex (RPC); the rice was harvested from Gimpo, Gyeonggi-do, Korea, in the fall of 2017. Prior to the experiment, $\mathrm{RH}$ was dried for $48 \mathrm{~h}$ at $45 \pm 5^{\circ} \mathrm{C}$ using a convection drying oven (FC-PO-1500, Lab House, Seoul, Korea) and stored in an automatic dehumidification desiccator. The moisture content of the RH was $4.6 \%$ based on its oven-dried weight.

\subsection{Compositional Analysis of Raw and Fractionated $R H$}

The carbohydrate components of the fractionated or untreated RH were subjected to a two-stage acid hydrolysis extraction process, which was standardized according to the procedure specified in the corresponding Laboratory Analytical Procedure of the National Renewable Energy Laboratory (NREL-LAP) [41]. In addition, in the analysis of liquid samples obtained during the fractionation, glucose and hemicellulosic sugar (xmg: xylose, mannose, and galactose) were analyzed by high-performance liquid chromatography (HPLC; 1260 Infinity, Agilent Technologies Inc., Santa Clara, CA, USA). The analytical column and detector were an Aminex HPX-87H organic acid column (Bio-Rad) and a refractive index detector (1260 RID, Agilent Technologies Inc.), respectively. The operating conditions for the HPLC column were $65{ }^{\circ} \mathrm{C}$ and a mobile-phase (sulfuric acid) flow rate of $0.6 \mathrm{~mL} / \mathrm{min}$.

\subsection{Experimental Setup and Operation of Bench-Scale Fractionation}

A tubular reactor was used to optimize the lab-scale alkaline fractionation process. The reactor was made of stainless steel (SS-316L) and had an internal diameter of $10.7 \mathrm{~mm}$ and a length of $150 \mathrm{~mm}$, with an internal volume of $13.5 \mathrm{~mL}$. Five hundred milligrams 
of oven-dried RH was placed in the reactor, and sufficient alkaline solution was added to give a solid-to-liquid ratio of 1:10. To increase the temperature of the reactor to the target temperature within approximately $1.0 \mathrm{~min}$, it was first immersed in the first heating bath (molten salt) set at $240^{\circ} \mathrm{C}$. When the temperature of the reactor reached the target temperature, it was quickly transferred to the second bath (silicone oil) set to the target reaction temperature $\left(116-184^{\circ} \mathrm{C}\right)$. After the reaction was conducted for a fixed period of time, the reactor was quenched in an ice-water bath to quickly stop the reaction.

The bench-scale $(30 \mathrm{~L})$ combined ball milling reactor used for the production of hemicellulosic sugar and black liquor via an alkaline fractionation of $\mathrm{RH}$ [42]; this reactor was designed to be capable of operating at $60 \mathrm{rpm}$ at a pressure of $20 \mathrm{~kg}_{\mathrm{f}} \mathrm{cm}^{-2}$ and a temperature of $200{ }^{\circ} \mathrm{C}$ (Sugaren Co. Ltd., Yongin, Korea). Alumina balls (HD, sphere type, $10 \mathrm{~mm}$ diameter, and $3.6 \mathrm{~g} \mathrm{~cm}^{-3}$ density) were additionally placed in the reactor to improve the mixing efficiency. The ball/biomass/alkaline solution ratio was 30:1:10 $(w / w / v)$. Upon completion of the reaction, the solid and liquid inside the reactor were separated. The remaining solid samples were washed and then used for glucose production by enzymatic hydrolysis.

\subsection{Optimization of the Process Variables Using Response Surface Methodology (RSM)}

A second-order model was used to fit the data individually for the response of hemicellulosic sugar extraction yield and de-ashing yield by the general model with three variables in the alkaline fractionation of rice husk: reaction temperature, reaction time, and $\mathrm{NaOH}$ concentration [43]. The range of process variables in the central composite design (CCD) are shown in Table 1.

Table 1. Process variables and their levels for $3^{3}$ central composite design (CCD).

\begin{tabular}{cccccc}
\hline \multirow{2}{*}{ Process Variables } & \multicolumn{5}{c}{ Coded Levels and Actual Conditions } \\
\cline { 2 - 6 } & $\mathbf{- 1 . 6 8}$ & $\mathbf{- 1}$ & $\mathbf{0}$ & $\mathbf{+ 1}$ & $\mathbf{+ 1 . 6 8}$ \\
\hline Temperature $\left({ }^{\circ} \mathrm{C}\right)$ & 116 & 130 & 150 & 170 & 184 \\
Time $($ min) & 6 & 20 & 40 & 60 & 74 \\
NaOH Conc. $(\%)$ & 1 & 2 & 3.5 & 5 & 6 \\
\hline
\end{tabular}

To achieve high hemicellulosic sugar extraction yield and de-ashing yield from $\mathrm{RH}$, the alkaline fractionation conditions were optimized by response surface methodology (RSM) based on the $3^{3}$ factorial CCD. To determine the optimal conditions for extracting hemicellulosic sugar and de-ashing, analysis of variance (ANOVA) and multiple regression analysis were performed using Design Expert (Ver 8, Stat-Ease, Minneapolis, MN, USA).

\subsection{Preparation of Nano-Structured Silica Powders from Black Liquor}

Nano-structured silica powders (NSP series) were obtained from a black liquor. A block diagram according to the preparing sequence and conditions is shown in Figure 1. In a typical preparation of NSP-1, $450 \mathrm{~mL}$ of the black liquor diluted with $50 \mathrm{~mL}$ of distilled water was used. First, the $\mathrm{pH}$ of the black liquor was adjusted to $\sim 7.0$ by addition of acetic acid. After the resulting solution was stirred for $12 \mathrm{~h}$ at room temperature $\left(\sim 25^{\circ} \mathrm{C}\right)$, it was centrifuged at $5000 \mathrm{rpm}$ for $5 \mathrm{~min}$; the supernatant was then decanted away. The remaining products were washed several times with distilled water and dried overnight at $80^{\circ} \mathrm{C}$. Finally, the dried powders were heat-treated at $600^{\circ} \mathrm{C}$ for $2 \mathrm{~h}$ under air atmosphere. Through this process, we obtained $\sim 15.5 \mathrm{~g}$ of silica powders per liter of black liquor. The overall synthesis procedure of NSP-2 and NSP-3 was similar to that of NSP-1, except that the $\mathrm{pH}$ of the black liquor was adjusted to $\sim 6.0$ and $\sim 8.0$, respectively. 


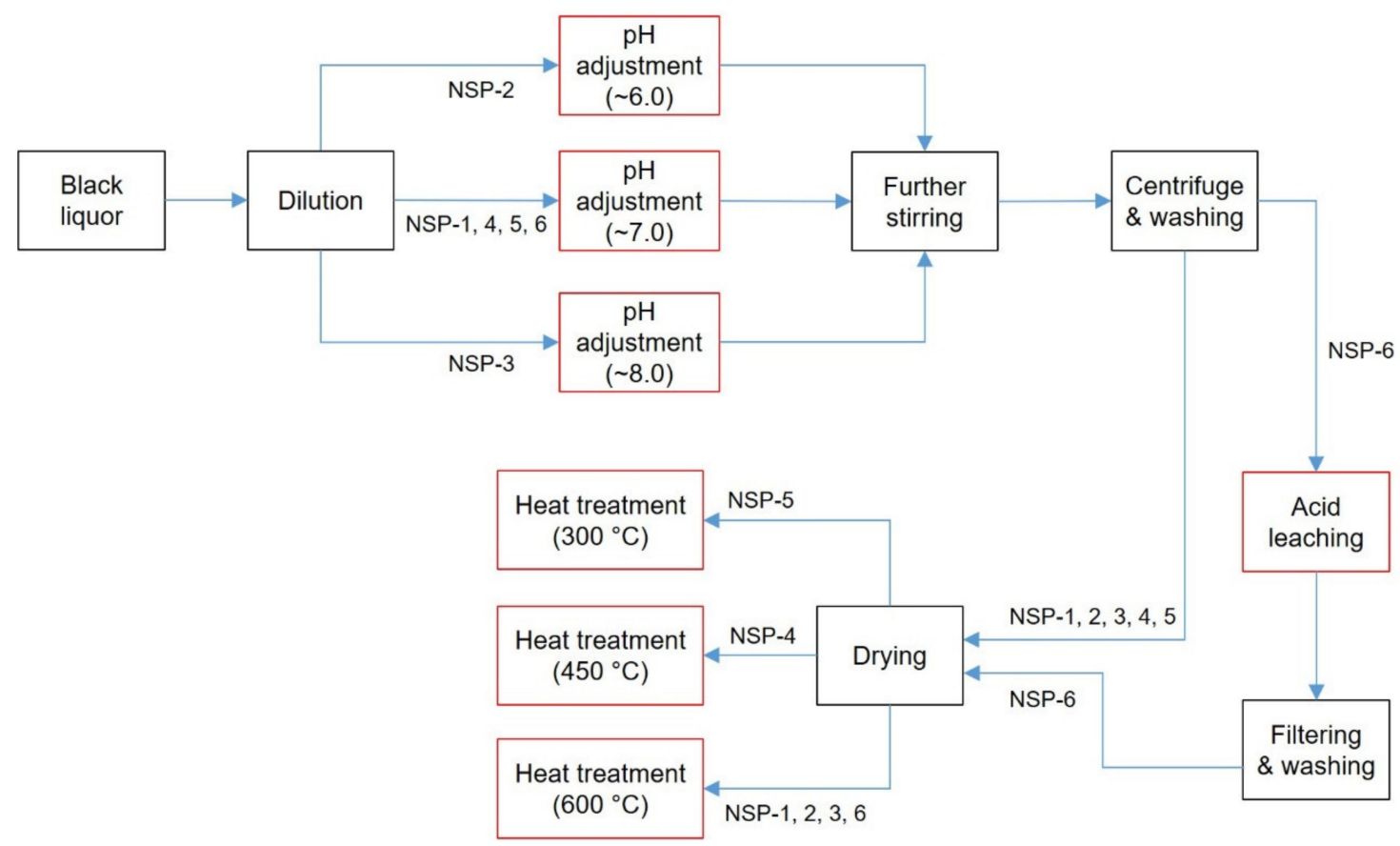

Figure 1. Block diagram depicting the preparation of nanostructured silica powder (NSP) from black liquor under different conditions.

In the case of NSP-4 and NSP-5, the overall synthetic procedure was the same as that of NSP-1, except that the heat-treatment temperatures at the last step ere $450{ }^{\circ} \mathrm{C}$ and $300{ }^{\circ} \mathrm{C}$, respectively. NSP- 6 was prepared by a procedure similar to that used for NSP-1, except that the dried powders at $80^{\circ} \mathrm{C}$ were further treated with $\mathrm{HCl}$ solution before the heat treatment at $600{ }^{\circ} \mathrm{C}$; specifically, the dried powders were placed in $100 \mathrm{~mL}$ of $10 \mathrm{wt} \%$ $\mathrm{HCl}$ solution and then stirred at $90^{\circ} \mathrm{C}$ for $2 \mathrm{~h}$. After reaction, the powders were filtered and washed with distilled water. After drying overnight at $80^{\circ} \mathrm{C}$, the final products were obtained by the heat treatment at $600{ }^{\circ} \mathrm{C}$ for $2 \mathrm{~h}$ under air atmosphere.

\subsection{Preparation of Cellulose Nano-Fibrils from Fractionated Residual Solid}

The two-stage bleaching process was performed using hydrogen peroxide $\left(\mathrm{H}_{2} \mathrm{O}_{2}\right)$ and chlorine dioxide $\left(\mathrm{ClO}_{2}\right)$ to remove residual lignin from fractionated solid phase. In the first step, the solid/liquid ratio was set to $10 \%$ using $5 \%(v / v) \mathrm{H}_{2} \mathrm{O}_{2}$, and reacted at $100{ }^{\circ} \mathrm{C}$ for $60 \mathrm{~min}$. In a second step using $5 \%(v / v) \mathrm{ClO}_{2}$, the $\mathrm{pH}$ was controlled to 3 to 4 using $\mathrm{CH}_{3} \mathrm{COOH}$, reacted at $70{ }^{\circ} \mathrm{C}$ for $90 \mathrm{~min}$, then washed with distilled water and dried at $45^{\circ} \mathrm{C}$. A $2 \mathrm{wt} . \%(w / v)$ dry solid suspension was prepared using distilled water, and $\mathrm{CNF}$ was prepared by grinding with a colloid milling device, Super Mass Colloider (MKCA6-5J, Masuko Sangyo Co., Kawaguchi, Japan). A non-porous grinder (MKGA10-80, Masuko Sangyo Co., Kawaguchi, Japan) that prevents contamination of bacteria and can add catalysts was used, for which the grinder interval was $150 \mu \mathrm{m}$ and the rotation speed was $1600 \mathrm{rpm}$.

\subsection{Material Characterization of Nano-Structured Silica Powders and Cellulose Nano-Fibril}

X-ray diffraction (XRD) patterns were obtained using a Rigaku D/Max 2500/PC diffractometer (Japan). The material morphologies were investigated by scanning electron microscopy (SEM; X-Max T50, Oxford Instruments, Abingdon, UK) and transmission electron microscopy (TEM; JEM-2000EX, JEOL Ltd., Tokyo, Japan). The nitrogen (N2) physisorption isotherms were obtained at $77 \mathrm{~K}$ using a Tristar II 3020 system (Micromeritics Inc., Norcross, GA, USA). The surface areas of materials were calculated from the measured isotherms according to the Brunauer-Emmett-Teller (BET) method, and the pore volumes were taken at the $\mathrm{P} / \mathrm{P}_{0} \approx 0.995$ single point. The pore size distributions of materials were 
calculated by the Barrett-Joyner-Halenda (BJH) method from the adsorption branches of the isotherms. The inorganic chemical composition and carbon content of silica were determined using a sequential X-ray fluorescence (XRF) spectrometer (ZSX100, Rigaku, Akishima, Japan) and an elemental analyzer (Elementar Analysensysteme $\mathrm{GmbH}$, vario MICRO cube, Langenselbold, Germany), respectively.

\section{Results}

\subsection{Compositional Analysis of Raw and Fractionated RH}

Table 2 summarizes the chemical constituents of the raw and $\mathrm{NaOH}$-fractionated $\mathrm{RH}$. The composition of carbohydrates in the raw $\mathrm{RH}$ was measured to be $35.6 \pm 0.8 \%$ of cellulose, $13.6 \pm 0.4 \%$ of hemicellulose, $0.8 \pm 0.1 \%$ of galactan, and $1.7 \pm 0.0 \%$ of arabinan; thus, the total carbohydrates account for $51.7 \pm 1.3 \%$. In addition, the noncarbohydrate component was analyzed to consist of $23.4 \pm 0.2 \%$ lignin, $4.2 \pm 0.1 \%$ extractives, $3.2 \%$ protein, $0.5 \%$ lipid, and $15.7 \pm 0.2 \%$ ash. Therefore, the mass closure of each constituent of raw $\mathrm{RH}$ was reached at $99.6 \pm 1.6 \%$ for oven-dried biomass. The results of the component analysis of the $\mathrm{NaOH}$-fractionated $\mathrm{RH}$ in the second row in Table 2 were used to compare the changes in content of each component.

Table 2. Chemical composition of raw and $\mathrm{NaOH}$-fractionated rice husk based on an oven-dry biomass.

\begin{tabular}{|c|c|c|c|c|c|c|c|c|c|c|c|}
\hline \multirow[b]{2}{*}{ Components } & \multicolumn{3}{|c|}{ Carbohydrates } & \multicolumn{2}{|c|}{ Lignin } & \multicolumn{2}{|c|}{ Extractives } & \multirow{2}{*}{$\underset{\text { (2) }}{\text { Protein }}$} & \multirow{2}{*}{$\underset{(3)}{\text { Lipid }}$} & \multirow[b]{2}{*}{ Ash } & \multirow{2}{*}{$\begin{array}{l}\text { Mass } \\
\text { Closure }\end{array}$} \\
\hline & Glucan & $\mathrm{XMG}^{(2)}$ & Arabinan & $\begin{array}{c}\text { Insoluble } \\
\text { Lignin }\end{array}$ & $\begin{array}{l}\text { Soluble } \\
\text { Lignin }\end{array}$ & Water & Ethanol & & & & \\
\hline \multirow{2}{*}{$\begin{array}{c}\text { Raw rice husk } \\
\text { Fractionated rice } \\
\text { husk }^{(1)}\end{array}$} & $35.6 \pm 0.8$ & $13.6 \pm 0.4$ & $0.8 \pm 0.1$ & $22.7 \pm 0.0$ & $0.7 \pm 0.2$ & $3.5 \pm 0.1$ & $0.7 \pm 0.0$ & 3.2 & 0.5 & $15.7 \pm 0.2$ & 97.9 \\
\hline & $73.9 \pm 1.1$ & $13.4 \pm 0.6$ & $1.1 \pm 0.2$ & $11.5 \pm 0.3$ & & & & & & & 99.9 \\
\hline
\end{tabular}

(1) $\mathrm{NaOH}$-fractionated at optimized reaction conditions; reaction temperature of $150{ }^{\circ} \mathrm{C}$, reaction time of $45 \mathrm{~min}$, and $\mathrm{NaOH}$. concentration of $6 \%(w / v)$ with solid remaining of 35.5\%. (2) XMG: Major component of hemicellulose (Xylan, Mannan, and Galactan). ${ }^{(3),(4)}$ Protein and lipid contents were analyzed by KFRI, Korea Food Research Institute. N-factor $=5.95$.

Only carbohydrate and lignin contents are shown for fractionated rice husk, because most of the noncarbohydrate components, including ash, were estimated to have been extracted into liquid by-product during the fractionation, resulting in no analysis. Similar studies have reported that alkaline fractionation facilitates the degradation of lignin and hemicellulose because of saponification of the intermolecular crosslinking between hemicellulose and lignin. In addition, significant changes in physical properties such as increased porosity, cellulose expansion and destruction of carbohydrate-lignin complexes can also be the cause $[44,45]$.

The cellulose content of the $\mathrm{NaOH}$-fractionated $\mathrm{RH}$ increased from $35.6 \%$ to $73.9 \%$, and the hemicellulosic sugar content was found to be very slightly reduced. Meanwhile, the lignin content was greatly reduced from $22.7 \%$ to $11.5 \%$. These values are relative, because the noncarbohydrate fraction and some of the hemicellulose and lignin fractions were solubilized during the fractionation; given the amount of residual solids, the hemicellulose and lignin fractions correspond to $26.2 \%$ cellulose, $4.8 \%$ hemicellulose, and $4.1 \%$ lignin based on the raw RH. These results are in good agreement with those of Shahabazuddin et al., who reported that the cellulose content increased from $32.7 \%$ to $51.7 \%$ and that the hemicellulose and lignin contents decreased from $18.1 \%$ to $16.1 \%$ and $26.7 \%$ to $12.3 \%$, respectively [46]. Compositional analysis was established from three replicate measurements performed independently; error values are expressed as standard deviations.

\subsection{Effects of Process Variables for Alkaline Fractionation}

The effects of independent variables, reaction temperature, reaction time, and $\mathrm{NaOH}$ concentration, were evaluated to maximize the extraction of lignin, ash, and hemicellulosic sugar. In the 17 experimental conditions investigated in this study, the hemicellulosic sugar extraction yields ranged from $21.7 \%$ to $77.4 \%$, and the de-ashing yields ranged from 69.2 to $95.6 \%$ (Table S1). In examining the influence of each independent variable, we 
observed that hemicellulosic sugar extraction and de-ashing yields tended to increase proportionally as the level of all of the independent variables increased. The effects of each independent variable on hemicellulosic sugar extraction and de-ashing yields were evaluated based on ANOVA (Table S2). The effect of $\mathrm{NaOH}$ concentration on the hemicellulosic sugar extraction yield was found to be greatest, followed by the effect of reaction time and temperature. By contrast, in the case of the de-ashing yield, significance was confirmed in the order of $\mathrm{NaOH}$ concentration, reaction temperature, and reaction time. The coefficients of determination $\left(R^{2}\right)$, which measure the fitness of the second-order regression equations for hemicellulosic sugar extraction and de-ashing yield, as derived using the CCD, were evaluated as 0.9803 and 0.8372 , respectively. The $p$-values were 0.0001 and 0.0406 , respectively, indicating that the confidence intervals were within $95 \%$. The highest yields of hemicellulosic sugar extraction and de-ashing at $150{ }^{\circ} \mathrm{C}, 40 \mathrm{~min}$ of reaction time, and $6 \%(w / v) \mathrm{NaOH}$ concentration were $77.4 \%$ and $95.6 \%$, respectively. These results are consistent with previous reports that lignin and ash were extracted as black liquor with increasing $\mathrm{NaOH}$ concentration.

\subsection{Multi-Objectives Optimization of the Alkaline Fractionation of RH}

The second-order polynomial equations related to hemicellulosic sugar extraction yield and de-ashing yield were obtained from the regression analysis and given by Equations (1) and (2).

$$
\begin{aligned}
\mathrm{Y}_{\mathrm{xmg}}=49.35+2.14 \times \mathrm{X}_{1}-0.34 \times \mathrm{X}_{2} & +14.56 \mathrm{X}_{3}-2.18 \mathrm{X}_{1} \mathrm{X}_{2}-2.84 \mathrm{X}_{1} \mathrm{X}_{3}-1.17 \mathrm{X}_{2} \mathrm{X}_{3} \\
-6.20 \mathrm{X}_{1}^{2}- & 1.60 \mathrm{X}_{2}^{2}+0.076 \mathrm{X}_{3}^{2} \\
\mathrm{Y}_{\text {de-ashing }}=93.65+1.25 \mathrm{X}_{1} & +1.68 \mathrm{X}_{2}+5.47 \mathrm{X}_{3}-0.10 \mathrm{X}_{1} \mathrm{X}_{2} \\
+ & 0.13 \mathrm{X}_{1} \mathrm{X}_{3}+0.25 \mathrm{X}_{2} \mathrm{X}_{3}+0.083 \mathrm{X}_{1}{ }^{2}-1.19 \mathrm{X}_{2}{ }^{2}-3.37 \mathrm{X}_{3}{ }^{2}
\end{aligned}
$$

where $X_{1}$ : reaction temperature; $X_{2}$ : reaction time; $X_{3}: \mathrm{NaOH}$ concentration.

The coefficients of determination $\left(R^{2}\right)$, which measure the fitness of the second-order regression equations for hemicellulosic sugar extraction and de-ashing yield, were evaluated as 0.9803 and 0.8372 , respectively, which further indicated that the model was suitable for adequately representing the real relationships among the selected reaction variables. The statistical significance of the model was evaluated by the F-test that showed that the regression was statistically significant. For the case of hemicellulosic sugar extraction yield, the "Prob $>F$ " represented as $p$-value for the model was $<0.0001$, which indicated that the model was statistically significant with a confidence level of $99.99 \%$.

The predicted maximum yield of hemicellulosic sugar extraction from the regression equation of dependent variable hemicellulosic sugar extraction yield was $74.7 \%$ at $148.1{ }^{\circ} \mathrm{C}$ reaction temperature, $27.0 \mathrm{~min}$ reaction time, and $5.9 \% \mathrm{NaOH}$ concentration, respectively. Furthermore, the predicted maximum de-ashing yield was $96.1 \%$ at $142.8^{\circ} \mathrm{C}$ reaction temperature, $60.6 \mathrm{~min}$ reaction time, and $4.9 \% \mathrm{NaOH}$ concentration. The conditions for highest yields of hemicellulosic sugar extraction and de-ashing were determined by the analysis of the statistical model generated.

Figure 2 attempts to represent the change of dependent variables by overlaid contour lines for the interactions between the independent variables; therefore, the gray-toned contours represent the changes in the de-ashing yield, and the black-toned contours were expressed for the changes in the hemicellulosic sugar extraction yield. Since a relatively high de-ashing yield was obtained in most of the experimental range, the optimization criterion was given priority to the range in which the hemicellulosic sugar extraction yield could be obtained more than $70 \%$. It was determined that the de-ashing yield was high, and the overlapping portion appeared to be suitable for the purpose of the processing, which was indicated in grayscale. Figure 2 a shows that over $72 \%$ hemicellulosic sugar extraction yield and $94 \%$ de-ashing yield can be obtained in the range of reaction temperature of about 146 to $158{ }^{\circ} \mathrm{C}$ and reaction time of about 41 to $55 \mathrm{~min}$. Likewise, in the case of reaction temperature, there was a possibility to obtain an hemicellulosic sugar extraction yield of $70 \%$ or more and a de-ashing yield of $93 \%$ or more in a wide range of about 140 to $160{ }^{\circ} \mathrm{C}$, 
but the $\mathrm{NaOH}$ concentration to meet these yields was determined to be possible only in a narrow experimental range of about $5.8-6.3 \%$ (Figure $2 b$ ).
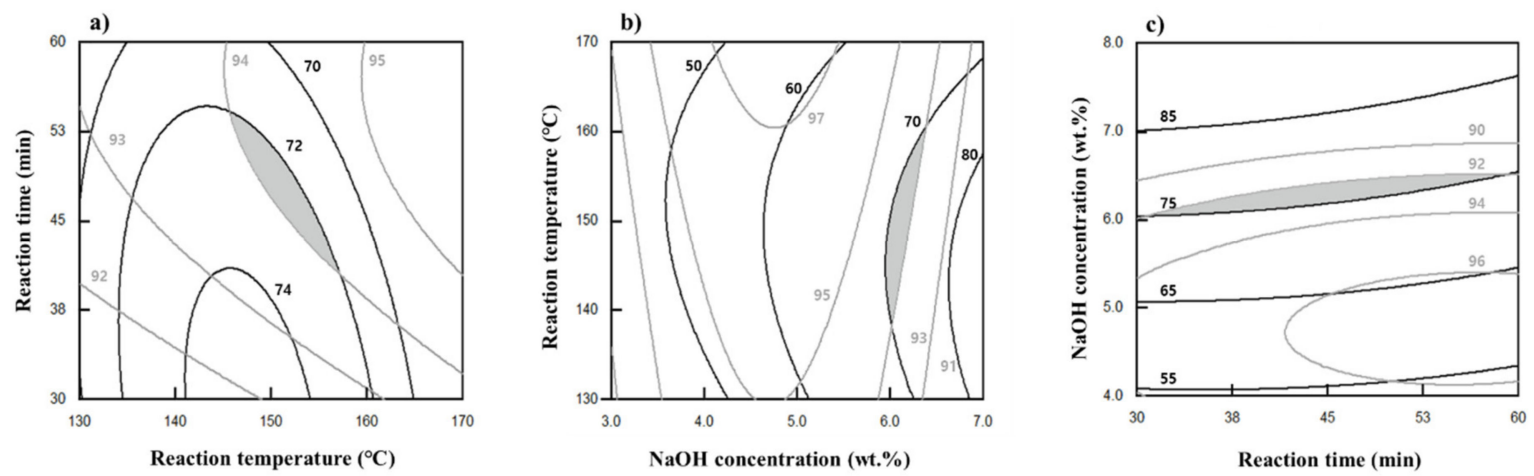

Figure 2. Multi-objective optimization on hemicellulosic sugar recovery and ash removal as a function of reaction temperature, reaction time and $\mathrm{NaOH}$ concentration, where, (a) $\mathrm{NaOH}$ concentration; 3.5 (w/v)\%, (b) Reaction time; 40 min., (c) Reaction temperature; $150{ }^{\circ} \mathrm{C}$.

It can be seen in Figure 2c that $\mathrm{NaOH}$ concentration greatly influences the sugar recovery and ash removal in the alkaline fractionation process of RHs. The reaction range capable of simultaneously matching the hemicellulosic sugar yield of $75 \%$ and the deashing yield of $92 \%$ or higher was possible in the entire range of reaction time. However, the effect of $\mathrm{NaOH}$ concentration was significant, as it was found to be possible only in the range of about $6.0 \%$ to $6.3 \%$.

By overlapping the response surfaces of the resultant dependent variables, the optimized reaction conditions were estimated with a reaction temperature of $149.8^{\circ} \mathrm{C}$, a reaction time of $45.1 \mathrm{~min}$, and a $\mathrm{NaOH}$ concentration of $5.9 \mathrm{wt} . \%$, under which the hemicellulosic sugar extraction and de-ashing yields were estimated to be $73.2 \%$ and $93.9 \%$, respectively. When the $\mathrm{RH}$ was fractionated under the optimized conditions; $150{ }^{\circ} \mathrm{C}$, a reaction time of $45 \mathrm{~min}$, and a $\mathrm{NaOH}$ concentration of $6.0 \mathrm{wt} . \%$, it was confirmed that the extraction yield of hemicellulosic sugar was $71.6 \%$ and the de-ashing yield was greater than $99 \%$, which are in good agreement with the estimated values obtained from the optimized conditions.

\subsection{Synthesis of Nano-Structured Silica from the Residual Black Liquor}

Residual black liquor is a type of basic silicate solution that contains both hemicellulosic sugar and lignin components. To obtain silica powders from black liquor preventing excessive precipitation of other components (e.g., lignin), the $\mathrm{pH}$ of black liquor was adjusted to neutral using a certain amount of acid solution. In this study, we used acetic acid instead of sulfuric acid for $\mathrm{pH}$ adjustment, because the former is weaker and less harmful than the latter. After purification of precipitated silica by centrifugation and washing, trace organic components were removed by heat treatment under an air atmosphere.

To prepare an initial test sample (NSP-1), the $\mathrm{pH}$ of black liquor was adjusted to approximately 7.0 using acetic acid, followed by heat treatment at a high temperature $\left(600^{\circ} \mathrm{C}\right)$ to completely remove the organic components. The XRD pattern of NSP-1 exhibited a broad diffraction near $20^{\circ}$, which is typical for amorphous silica (Figure 3a). It was seen that silica content among the inorganic components of NSP-1 was as high as $98.0 \%$, and a small amount $(1.76 \%)$ of sodium compound was also measured. SEM and TEM images of NSP-1 showed that the small nano-particles aggregated into large particles with sizes of a few hundred nanometers (Figure $3 b, c)$. These types of hierarchical nano-structures impart NSP-1 with a large surface area of $175 \mathrm{~m}^{2} \mathrm{~g}^{-1}$ and a pore volume of $0.81 \mathrm{~cm}^{3} \mathrm{~g}^{-1}$ (Table 3). 
(a)

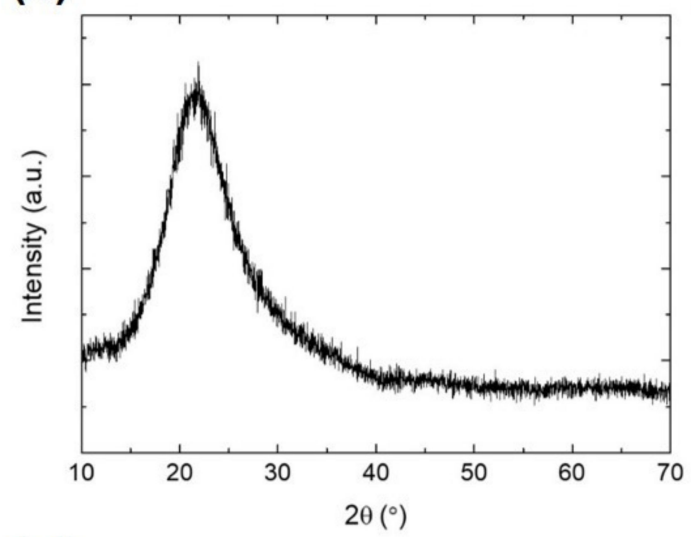

(c)

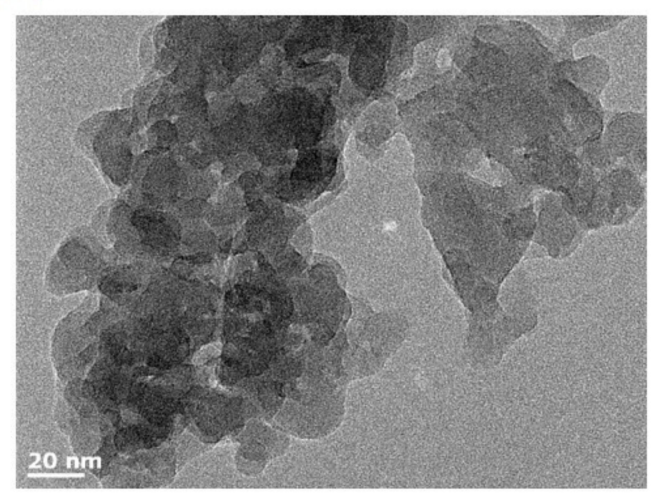

(b)

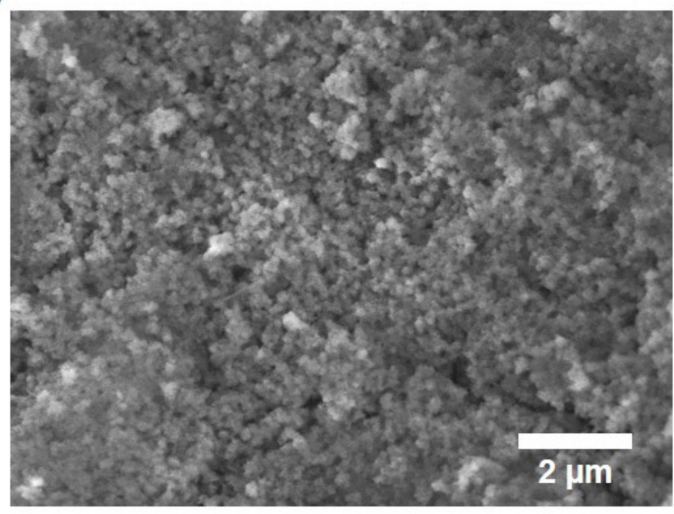

(d)

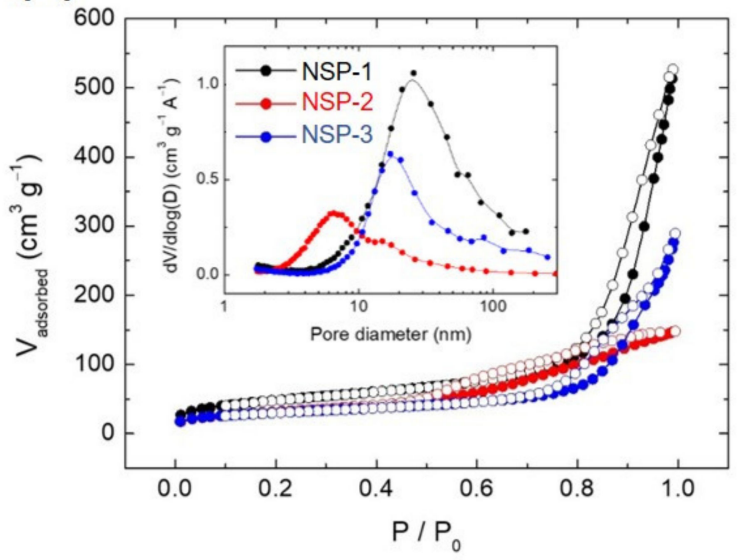

Figure 3. (a) XRD pattern, (b) SEM image, and (c) TEM image of NSP-1. (d) N2 physisorption isotherms and pore size distributions (inset) of NSP-1, NSP-2, and NSP-3.

Table 3. Experimental conditions and characterization results of NSP series.

\begin{tabular}{|c|c|c|c|c|c|c|}
\hline & NSP-1 & NSP-2 & NSP-3 & NSP-4 & NSP-5 & NSP-6 \\
\hline $\mathrm{pH}$ control & $\sim 7.0$ & $\sim 6.0$ & $\sim 8.0$ & $\sim 7.0$ & $\sim 7.0$ & $\sim 7.0$ \\
\hline Acid leaching & - & - & - & - & - & $\mathrm{O}$ \\
\hline $\begin{array}{l}\text { Heat treatment } \\
\text { temperature }\left({ }^{\circ} \mathrm{C}\right)\end{array}$ & 600 & 600 & 600 & 450 & 300 & 600 \\
\hline Surface area $\left(\mathrm{m}^{2} \mathrm{~g}^{-1}\right)$ & 175 & 113 & 109 & 273 & 328 & 392 \\
\hline Pore volume $\left(\mathrm{cm}^{3} \mathrm{~g}^{-1}\right)$ & 0.81 & 0.23 & 0.45 & 0.57 & 0.61 & 0.65 \\
\hline Main pore size $(\mathrm{nm})$ & $\sim 25$ & $\sim 7$ & $\sim 20$ & $\sim 10$ & $\sim 10$ & $\sim 10$ \\
\hline $\begin{array}{l}\mathrm{SiO}_{2}(\%) \text { among the } \\
\text { inorganic components }\end{array}$ & 98.0 & 95.5 & 97.2 & 98.2 & 98.1 & 99.8 \\
\hline
\end{tabular}

In the synthesis procedure, it was confirmed that the $\mathrm{pH}$ of black liquor and the heattreatment temperature affected the textural properties of silica products substantially. NSP2 and NSP-3 were obtained using the same procedure used for NSP-1, except that the $\mathrm{pH}$ levels of the black liquor were adjusted to approximately 6.0 and 8.0, respectively. Although the $\mathrm{pH}$ levels of NSP-2 and NSP-3 only differed from that of NSP-1 by approximately $\pm 1.0 \mathrm{pH}$ unit, their surface areas and pore volumes were noticeably small. NSP-2 exhibited a surface area of $113 \mathrm{~m}^{2} \mathrm{~g}^{-1}$ and a pore volume of $0.23 \mathrm{~cm}^{3} \mathrm{~g}^{-1}$. A similar tendency was observed for NSP-3 (Table 3), which exhibited a surface area of $109 \mathrm{~m}^{2} \mathrm{~g}^{-1}$ and a pore volume of $0.45 \mathrm{~cm}^{3} \mathrm{~g}^{-1}$. We speculated that these differences in textural properties resulted from the different rates of condensation reactions. After the formation of silicic acid by the addition of acetic acid, the condensation reaction of silicic acid was strongly dependent 
on the $\mathrm{pH}$ of the reactant solution [47]. Since the formation of the silica framework was affected by the condensation reaction rate, the textural properties of NSP powder were also altered by the $\mathrm{pH}$ of the solution.

\subsection{Optimization for the Synthesis of Nano-Structured Silica with Large Surface Area}

NSP-4 and NSP-5 were prepared following the same synthesis procedure used for NSP-1, except that the heat-treatment temperature at the last step was decreased to $450{ }^{\circ} \mathrm{C}$ and $300{ }^{\circ} \mathrm{C}$, respectively. Because of the lower heat-treatment temperatures, the surface area of the silica substantially increased (Table 3). Between NSP-4 and NSP-5, NSP-5 showed a surface area of $328 \mathrm{~m}^{2} \mathrm{~g}^{-1}$, which was nearly two times larger than that of NSP-1.

The main pore sizes of NSP-4 and NSP-5 were approximately $10 \mathrm{~nm}$, whereas that of NSP-1 was approximately $25 \mathrm{~nm}$ (Figure $4 \mathrm{a}$ ). This phenomenon might be induced by the residual sodium contents in the NSP powders, because the melting points of sodium silicates are substantially lower than that of pure silica [48]. Therefore, a small sodium content could reduce the melting point of the silica. In addition, because the particle size decreased to the nano-scale, the melting point of the material also decreased [49]. Accordingly, the nanosized silica framework of the NSP series could be easily melted and aggregated even at $600{ }^{\circ} \mathrm{C}$. This process leads to the generation of large mesopores through the collapse of small mesopores, resulting in the decrease of surface area. Inevitably, because of the low heat-treatment temperature, the carbon content $(0.61 \mathrm{wt}$ \% $)$ of NSP-5 was greater than that (0.06 wt.\%) of NSP-1. However, we found that nano-structured silica with a high surface area could be readily prepared through a simple optimization of the established process.

(a)
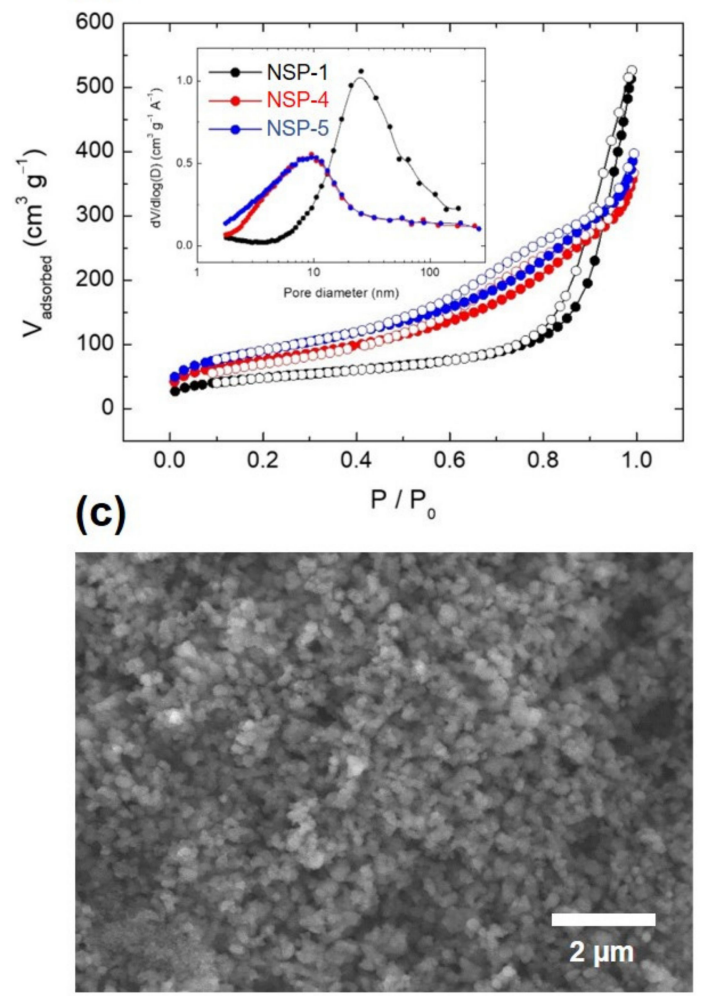

(b)

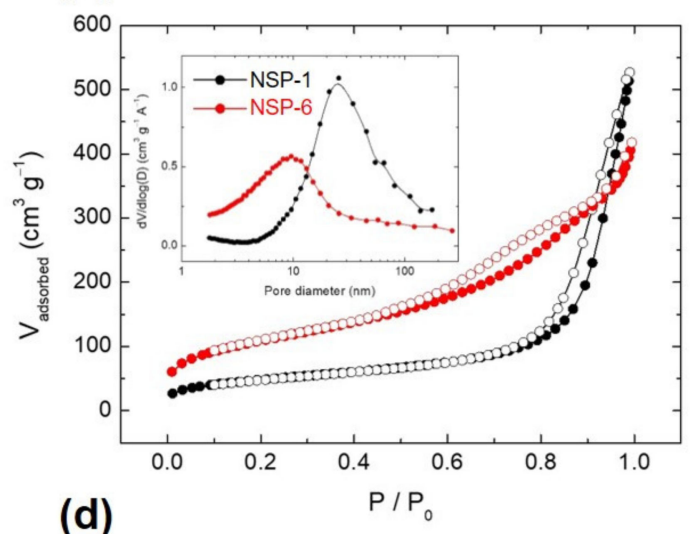

(d)

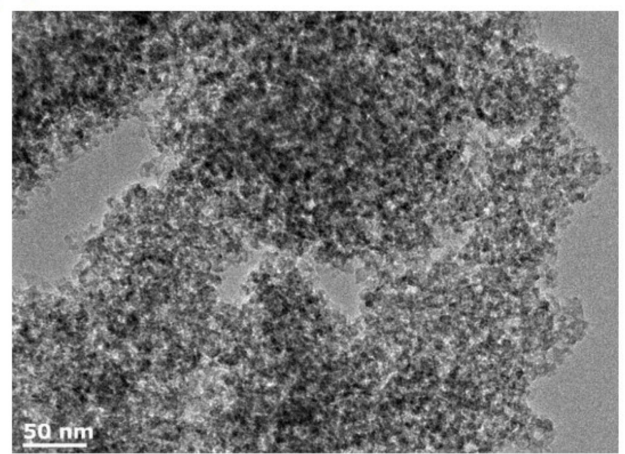

Figure 4. (a) $\mathrm{N}_{2}$ physisorption isotherms and pore size distributions (inset) of NSP-1, NSP-4, and NSP-5. (b) N2 physisorption isotherms and pore size distributions (inset) of NSP-1 and NSP-6. (c) SEM and (d) TEM images of NSP-6.

It was also found that high purity silica can be obtained without compromising textural properties through additional acid leaching. After centrifugation and washing, dried powders were further treated with $\mathrm{HCl}$ solution before heat treatment at high temperature. 
Through this acid leaching process, residual sodium compounds could be completely removed. XRF analysis results showed that the purity of the silica product (NSP-6) was as high as $99.8 \%$, but that of the sodium compound was less than $0.2 \%$. Interestingly, although NSP- 6 was obtained through heat treatment at $600{ }^{\circ} \mathrm{C}$, it retained a high surface area of $392 \mathrm{~m}^{2} \mathrm{~g}^{-1}$ with a main pore size of $\sim 10 \mathrm{~nm}$ (Table 3 and Figure $4 \mathrm{~b}$ ). In comparison with the TEM image in Figure 4c, the high-magnification TEM image of NSP-6 (Figure $4 \mathrm{~d}$ ) clearly showed the preservation of small-sized nanopores without agglomeration of the framework. This result supports the fact that the residual sodium content strongly affects the surface area of silica by deforming the silica framework during heat treatment at high temperatures. Because of its high treatment temperature, NSP- 6 contained practically no carbon $(0.06 \mathrm{wt} . \%)$. Therefore, high-purity silica with a large surface area could be successfully obtained from a black liquor. In particular, the surface area of NSP-6 is much greater than that of RH-derived silica prepared in previous studies [50,51], despite the absence of the use of additional surfactants or block copolymers.

\subsection{Characteristics of CNF Prepared from Fractionated Residual Solid}

Figure 5 shows the changes in chemical composition of raw $\mathrm{RH}$ and sequentially treated RH fibers. The untreated RH showed component content of cellulose $35.6 \%$, hemicellulose $13.6 \%$, lignin $23.4 \%$, and ash $15.7 \%$. The relative composition of the residual solid fractionated by $\mathrm{NaOH}$ showed $70.8 \%$ of cellulose, $12.3 \%$ of hemicellulose, $12.2 \%$ of lignin, and $0 \%$ of ash, confirming that all ash and a significant amount of lignin were removed through the optimized $\mathrm{NaOH}$ fractionation, whose conditions were $150{ }^{\circ} \mathrm{C}$, a reaction time of $45 \mathrm{~min}$, and a $\mathrm{NaOH}$ concentration of $6.0 \mathrm{wt} . \%$. As a result of the first bleaching stage $\left(\mathrm{H}_{2} \mathrm{O}_{2}\right)$ on the $\mathrm{NaOH}$ fractionated residual solid, the relative content of the 1st bleached solid was shown as cellulose of $81.1 \%$, hemicellulose of $12.0 \%$, and lignin of $6.1 \%$, representing that some of the lignin was removed. In the case of the second bleached $\left(\mathrm{ClO}_{2}\right) \mathrm{RH}$, the relative composition of cellulose $85.2 \%$, hemicellulose $10.4 \%$, and lignin $0.6 \%$ were shown, so that most of the lignin was removed, resulting in highly pure cellulose.

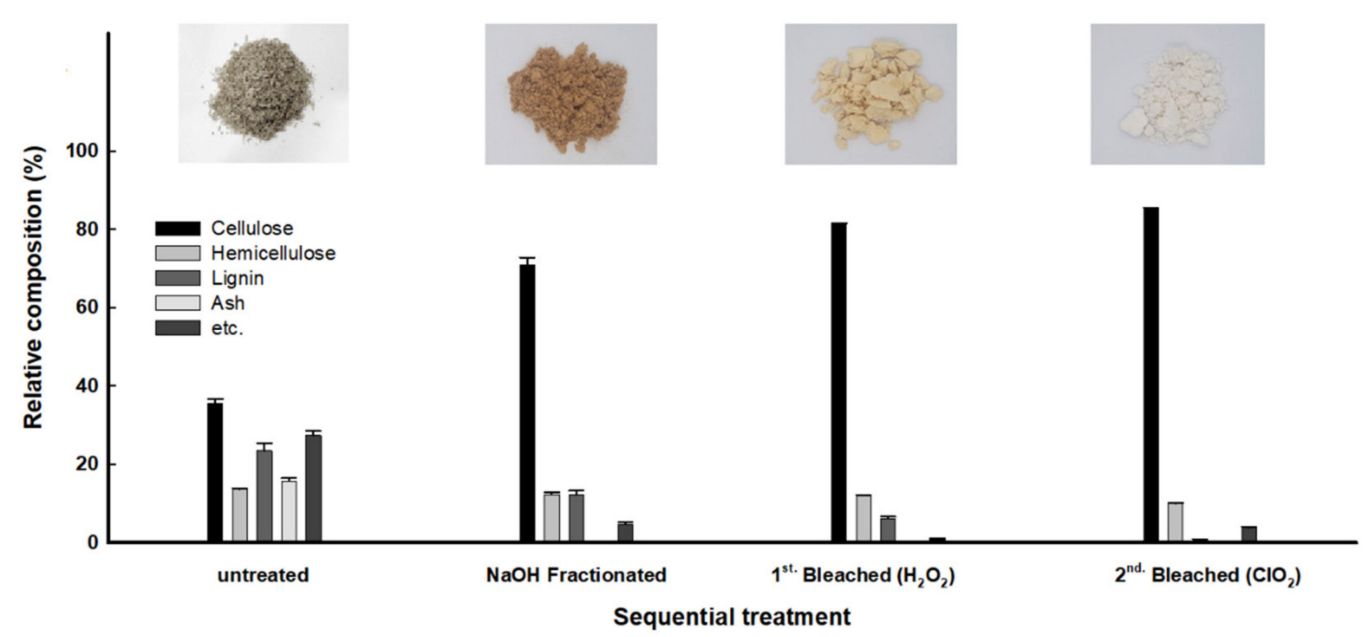

Figure 5. Changes in chemical composition and whiteness of rice husk fiber according to sequential treatment: untreated $\mathrm{RH}, \mathrm{NaOH}$ fractionated $\mathrm{RH}$ fiber, first bleached $\mathrm{RH}$ fiber, second bleached $\mathrm{RH}$ fiber.

In addition, figures of residual solids for each sequential bleaching were intended to be shown at the top of Figure 5. After the second-stage bleaching process, the residual solid had a white color, which was believed to be due to the removal of lignin and other impurities as the bleaching proceeds sequentially. The change in the colors of the residual solids in each sequence well explained the change in the chemical composition as the bleaching progresses. 
Figure 6a shows the results of XRD analysis to compare the change in crystallinity of $\mathrm{RH}$ and $\mathrm{RH}$ fibers according to each sequence. $\mathrm{RH}$ raw material, $\mathrm{NaOH}$-treated $\mathrm{RH}$ fiber, and first-stage bleached RH fiber showed Cellulose I form, which is the crystal structure of lignocellulose that exists in nature. On the other hand, CNF obtained after second-stage bleaching showed a Cellulose II form. It is believed that this is because the number of hydrogen bonds between molecules increases as hydroxyl groups are exposed due to mechanical shear and friction forces, resulting in a more stable crystal structure. The crystallization index $(\mathrm{CrI})$ at each stage of bleaching was the lowest at $37.3 \%$ in $\mathrm{RH}$ raw samples, $51.6 \%$ in $\mathrm{NaOH}$-treated $\mathrm{RH}$ fiber, and $60.5 \%$ in first-stage bleached $\mathrm{RH}$ fiber. On the other hand, the crystallinity of the CNF obtained after proceeding to the secondstage bleaching was measured to be $57.1 \%$, which was slightly lowered. This result is in good agreement with the results of Liu et al., which suggested that the crystallinity of $\mathrm{CNF}$ increased as the proportion of cellulose increases due to the removal of amorphous components such as lignin or hemicellulose during chemical bleaching step [52].

(a)

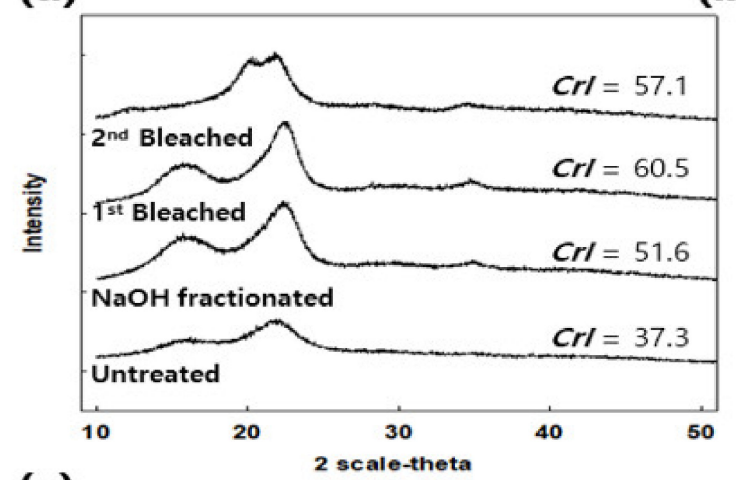

(c)

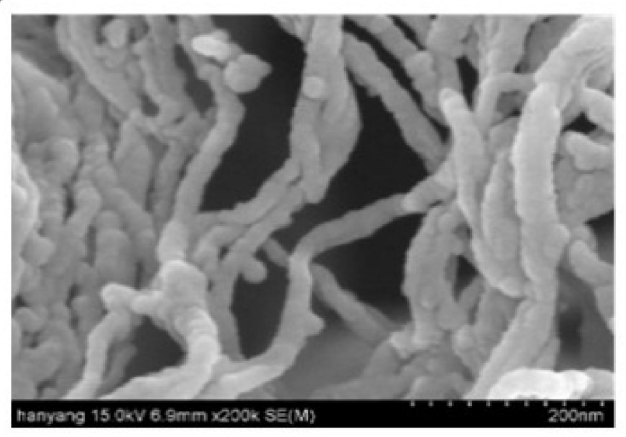

(b)

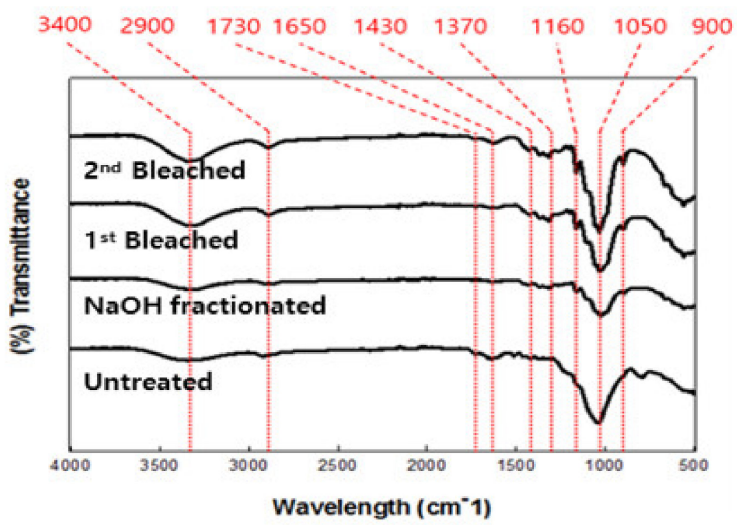

(d)

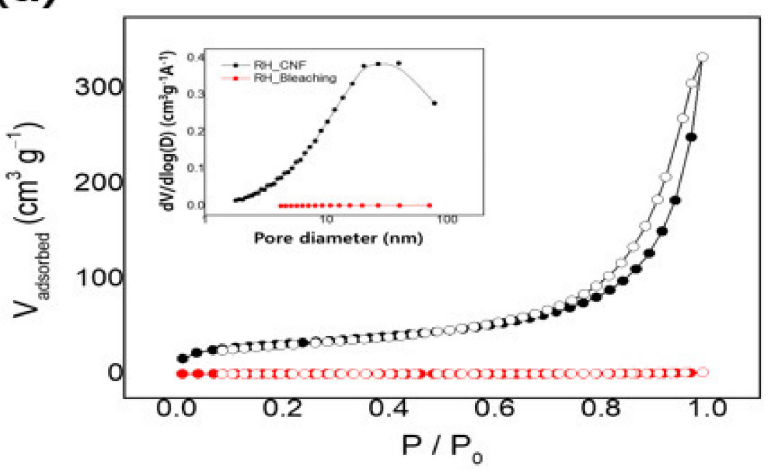

Figure 6. (a) XRD patterns, (b) FT-IR patterns, (c) SEM image of CNF, (d) $\mathrm{N}_{2}$ physisorption isotherms and pore size distributions (inset) of $\mathrm{NaOH}+$ bleaching treated $\mathrm{RH}, \mathrm{CNF}$.

Figure $6 \mathrm{~b}$ shows the FT-IR spectra of raw RH and RH fibers obtained by chemical bleaching for each stage. All samples exhibited major absorption areas in the range of 900-1600 $\mathrm{cm}^{-1}, 2900-3400 \mathrm{~cm}^{-1}$. Compared to the raw $\mathrm{RH}$ raw material, the narrow and high peak of $3335-3344 \mathrm{~cm}^{-1}$ in the chemically treated $\mathrm{RH}$ fiber indicates that it contains more -OH groups. The 1159-1108 cm $\mathrm{cm}^{-1}$ peak, $1027-1051 \mathrm{~cm}^{-1}$ peak, and $896-897 \mathrm{~cm}^{-1}$ peak represent typical $\beta-(1-4)$ glycosidic bonds in cellulose including $\mathrm{C}-\mathrm{O}-\mathrm{C}$ stretching and pyranose ring skeleton vibration. As the bleaching progressed, more significant effects were observed, which is believed to be due to the increase in the proportion of cellulose due to the removal of non-cellulosic substances by chemical bleaching. The peak at $1734 \mathrm{~cm}^{-1}$ in the spectrum of the $\mathrm{RH}$ raw material (a) is due to $\mathrm{C}=\mathrm{O}$ bonding, and it was found that most of the hemicellulose and lignin components were removed as the peak disappeared in the 
treated RH fiber. In the CNF spectrum (d), characteristic peaks were 1429 and $1370 \mathrm{~cm}^{-1}$, which were related to $\mathrm{CH}_{2}$ bending and $\mathrm{O}-\mathrm{H}$ bending, respectively.

As a result of the FE-SEM analysis, it was confirmed that the nano-fibrillation of the milled RH fibril was properly performed compared to the unmilled RH fiber (image is not shown) as shown in Figure 6c. Before colloid milling, the diameter of RH fiber was observed to be 10-50 $\mu \mathrm{m}$, and after colloid milling, the diameter of RH fibril was observed to be 19-21 nm, confirming that the nano-sized fibril was properly formed.

In order to observe the structural characteristics of CNF, BET analysis was performed (Figure 6d), and the results of analysis of the specific surface area, pore volume, and pore size of RH fibrils before and after colloid milling are summarized in Table 4 . The surface area of RH fibril before milling was $0.79 \mathrm{~m}^{2} \mathrm{~g}^{-1}$, the pore volume was $0.0026 \mathrm{~cm}^{3} \mathrm{~g}^{-1}$, and the pore size was $14.81 \mathrm{~nm}$. After milling, the surface area, pore volume, the pore size of CNF were all increased; i.e., $110.52 \mathrm{~m}^{2} \mathrm{~g}^{-1}, 0.52 \mathrm{~cm}^{3} \mathrm{~g}^{-1}$, and $15.82 \mathrm{~nm}$, respectively. It was confirmed that the aspect ratio and specific surface area were greatly improved during colloid milling, and colloid milling can be used as an effective CNF manufacturing method.

Table 4. Effects of colloid milling treatment on characteristics of CNF.

\begin{tabular}{cccc}
\hline Sample & $\begin{array}{c}\text { BET Surface Area } \\
\left(\mathbf{m}^{\mathbf{2}} \mathbf{g}^{-\mathbf{1})}\right.\end{array}$ & $\begin{array}{c}\text { Pore Volume } \\
\left(\mathbf{c m}^{\mathbf{3}}\right)\end{array}$ & $\begin{array}{c}\text { Pore Size } \\
(\mathbf{n m})\end{array}$ \\
\hline Before milling treatment & 0.79 & $<0.01$ & 14.81 \\
After milling treatment & 110.52 & 0.52 & 15.82 \\
\hline
\end{tabular}

\subsection{Overall Mass Balance on the Comprehensive Utilization of $R H$}

Figure 7 summarizes the simplified flow diagram and overall mass balance for each sequential process aimed at producing high value-added bio-based materials from $\mathrm{RH}$. Based on $1000 \mathrm{~g}$ of RH input, the cellulose and hemicellulose, lignin, and ash contents were $356,136,227$, and $157 \mathrm{~g}$, respectively. Under the optimized fractionation conditions, approximately $64.5 \%$ of the input biomass mass was solubilized into the black liquor, with $26.2 \%$ cellulose, $64.7 \%$ hemicellulose, and nearly $100 \%$ of ash from the raw $\mathrm{RH}$.

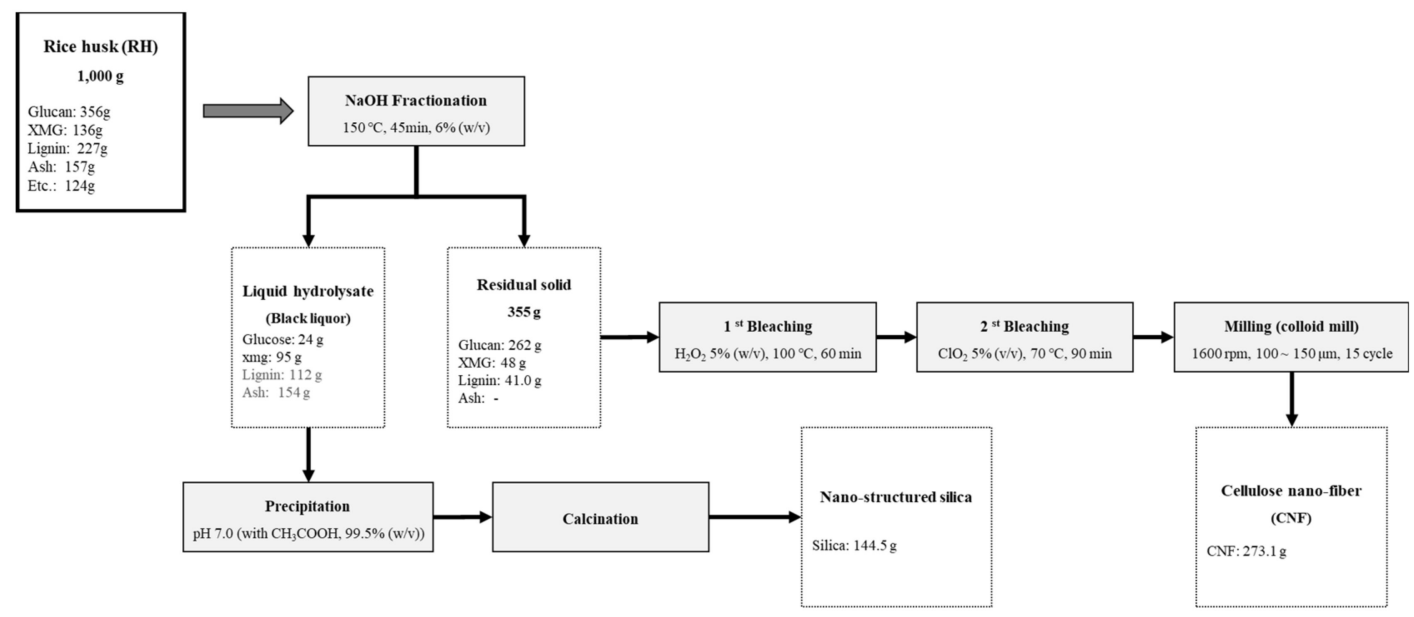

Figure 7. Simplified flow diagram of the RH process including the overall mass balance of $\mathrm{RH}$ fractionation process for cellulose nano-fibril and nano-structured silica.

Black liquor from alkaline fractionation contained $24 \mathrm{~g}$ of glucose, $95 \mathrm{~g}$ of hemicellulosic sugar, and $152 \mathrm{~g}$ of ash, and $262 \mathrm{~g}$ of cellulose and $48 \mathrm{~g}$ of hemicellulose were retained unhydrolyzed in $355 \mathrm{~g}$ of the residual solid based on $1 \mathrm{~kg}$ of raw $\mathrm{RH}$. During the alkaline fractionation process, the undetected $79 \mathrm{~g}$ of glucose, which corresponded to $20.3 \%$ of cellulose, was presumed to be in the sugar filtrate as a cello-oligomer, because small 
amounts of degradation products from glucose, such as HMF and levulinic acid, were found in the analysis.

The black liquor resulting from the alkaline fractionation was subjected to consecutive precipitation and calcination, yielding $143 \mathrm{~g}$ of high-purity nano-structured silica.

In order to produce the CNF from the fractionated solid, a two-stage bleaching process using hydrogen peroxide and chlorine dioxide followed by colloid milling was performed, which resulted in $273.1 \mathrm{~g}$ of CNF ( $80.1 \%$ of cellulose content). After the bleaching process, $41.6 \mathrm{~g}(12.2 \%)$ of lignin was almost removed, and the whiteness of the cellulose could be enhanced. As a result, $96.3 \%$ of $283.5 \mathrm{~g}$ of cellulose was converted to CNF throughout the colloid milling process.

\section{Discussion}

For production of high value-added materials from lignocellulosic biomass, there have been many previous reports on the cellulose nano-crystals [53] and silica [54]. In addition, recent studies have focused on the opportunity to simultaneously fractionate and recover the useful components of biomass through unique fractionation methods using various catalytic solutions $[55,56]$.

In this work, an alkaline fractionation was selected for the fractionation of the lignocellulosic materials, because the $\mathrm{NaOH}$ solutions are widely employed to remove lignin from wood and non-woody lignocellulosic materials [57,58]. It should be noted that the alkaline fractionation is also able to effectively solubilize hemicellulose, residual extractives, and ashes [59]. It is also important that the large amount of ash confers RH an outstanding recalcitrance toward biological and environmental threats. It was observed that the 30 L-bench scale alkaline fractionation completely removed ash from $\mathrm{RH}$, in addition to the effective production of hemicellulosic sugars. We have already confirmed that the integration of mechanical and chemical pretreatment can be implemented in a large-scale reactor system [37].

$\mathrm{RH}$ is a naturally ash-rich agricultural by-product, which has more than $90 \%$ of this inorganic fraction as a pure silica [60], and the natural silica obtained from it represents an economically viable raw material that can be effectively used in life science and health care industries including cosmetics and pharmaceuticals. In this study, it was verified that silica can be recovered from the fractionated liquid phase generated and there was an advantage in recovering cellulose nanofibrils $(\mathrm{CNF})$ in solid phase. $\mathrm{CNF}$ are attracting much attention due to their high nano-sized surface area, low density and high mechanical strength, as well as their solubility and biodegradability properties. In these days, CNF is promising to be used in a variety of applications in fields such as paper, composites, packaging, coatings, biomedicine, and automobiles due to its outstanding properties [61].

\section{Conclusions}

One of the most impeding negatives for the biorefinery industry is how to improve low economics. To overcome this problem, it is important to achieve effective utilization of lignocellulosic biomass and improve overall process economy by simultaneous production of high value-added materials. In our study, we have demonstrated the excellent properties, physical properties, and purity of the fractions produced through the fractionation method, which can maximize the added value of each component. In conclusion, it was confirmed that rice husk is a resource with very high economic potential. For this reason, this study attempted to increase the added value of by-products for the development of efficient biorefinery process technology, and is currently conducting research on technologies and applications such as separation/purification of high value-added silica and production of cellulose fiber. 
Supplementary Materials: The following are available online at https:/ /www.mdpi.com/2071-105 0/13/4/1951/s1: Figure S1. Central composite experimental design and responses obtained for the alkaline fractionation of rice husk on the yields of xmg extraction and de-ashing, Figure S2. Analysis of variance (ANOVA) for the adjusted quadratic model for alkaline fractionation of rice husk on the xmg extraction yield and de-ashing yield.

Author Contributions: Conceptualization: H.J.J., J.C. and H.K.; methodology: H.J.J. and H.K.; validation: H.K.; formal analysis: H.J.J. and J.C.; investigation: H.J.J., J.C. and K.K.O.; resources: H.J.J.; data curation: H.J.J., J.C. and H.K.; writing-original draft preparation: K.K.O. and J.C.; writing-review and editing: K.K.O. and J.C.; visualization: H.J.J.; supervision: K.K.O.; project administration: K.K.O.; funding acquisition: K.K.O. and J.C. All authors have read and agreed to the published version of the manuscript.

Funding: This work was supported by the R\&D program of Korea Institute of Energy Technology Evaluation and Planning (KETEP) grant funded by the Ministry of Trade, Industry, and Energy (MOTIE), the Republic of Korea (No. 20183030091950).

Institutional Review Board Statement: Not applicable.

Informed Consent Statement: Not applicable.

Data Availability Statement: Not applicable.

Conflicts of Interest: The authors declare that they have no known competing financial interests or personal relationships that could have appeared to influence the work reported in this paper.

\section{References}

1. Jiang, Z.; Hu, D. Molecular mechanism of anionic dyes adsorption on cationized rice husk cellulose from agricultural wastes. J. Mol. Liq. 2019, 276, 105-114. [CrossRef]

2. Mansilla, H.D.; Baeza, J.; Urzua, S.; Maturana, G.; Villase, J.; Duran, N. Acid catalysed hydrolysis of rice hull: Evaluation of furfural production. Bioresour. Technol. 1998, 66, 189-193. [CrossRef]

3. Menon, V.; Rao, M. Trends in bioconversion of lignocellulose: Biofuels, platform chemicals and biorefinery concept. Prog. Energy Combust. Sci. 2012, 38, 522-550. [CrossRef]

4. Barana, D.; Salanti, A.; Orlandi, M.; Ali, D.S.; Zoia, L. Biorefinery process for the simultaneous recovery of lignin, hemicelluloses, cellulose nanocrystals and silica from rice husk and Arundo donax. Ind. Crops Prod. 2016, 86, 31-39. [CrossRef]

5. Johar, N.; Ahmad, I.; Dufresne, A. Extraction, preparation and characterization of cellulose fibres and nanocrystals from rice husk. Ind. Crops Prod. 2012, 37, 93-99. [CrossRef]

6. Hanafi, E.; Khadrawy, H.; Ahmed, W.; Zaabal, M. Some observations on rice straw with emphasis on updates of its management. World Appl. Sci. J. 2012, 16, 354-361.

7. Arai, H.; Hosen, Y.; van Nguyen, P.H.; Thi, N.T.; Huu, C.N.; Inubushi, K. Greenhouse gas emissions from rice straw burning and straw-mushroom cultivation in a triple rice cropping system in the Mekong Delta. Soil Sci. Plant Nutr. 2015, 61, 719-735. [CrossRef]

8. Liu, C.; Lu, M.; Cui, J.; Li, B.; Fang, C.M. Effects of straw carbon input on carbon dynamics in agricultural soils: A meta-analysis. Glob. Chang. Biol. 2014, 20, 1366-1381. [CrossRef] [PubMed]

9. Ray, D.K.; Ramankutty, N.; Mueller, N.D.; West, P.C.; Foley, J.A. Recent patterns of crop yield growth and stagnation. Nat. Commun. 2012, 3, 1293-1300. [CrossRef] [PubMed]

10. Conrad, R. Microbial ecology of methanogens and methanotrophs. Adv. Agron. 2007, 96, 1-63. [CrossRef]

11. Salanti, A.; Zoia, L.; Orlandi, M.; Zanini, F.; Elegir, G. Structural characterization and antioxidant activity evaluation of lignins from rice husk. J. Agric. Food. Chem. 2010, 58, 10049-10055. [CrossRef] [PubMed]

12. Liou, T.H. Preparation and characterization of nano-structured silica from rice husk. Mater. Sci. Eng. A. 2004, 364, 313-323. [CrossRef]

13. Lemons e Silva, C.F.; Schirmer, M.A.; Maeda, R.N.; Barcelos, C.A.; Pereira, N. Potential of giant reed (Arundo donax L.) for second generation ethanol production. Electron. J. Biotechnol. 2015, 18, 10-15. [CrossRef]

14. Wei, G.Y.; Lee, Y.J.; Kim, Y.J.; Jin, I.H.; Lee, J.H.; Chung, C.H.; Lee, J.W. Kinetic study on the pretreatment and enzymatic saccharification of rice hull for the production of fermentable sugars. App l. Biochem. Biotechnol. 2010, 162, 1471-1482. [CrossRef] [PubMed]

15. Yu, J.; Zhang, J.B.; He, J.; Liu, Z.D.; Yu, Z.N. Combinations of mild physical or chemical pretreat ment with biological pretreatment for enzymatic hydrolysis of rice hull. Bioresour. Technol. 2009, 100, 903-908. [CrossRef]

16. Megawati, M.; Sediawan, W.B.; Sulistyo, H.; Hidayat, M. Kinetics of sequential reaction of hydroly sis and sugar degradation of rice husk in ethanol production: Effect of catalyst concentration. Bioresour. Technol. 2011, 102, 2062-2067. [CrossRef] [PubMed] 
17. Banerjee, S.; Sen, R.; Pandey, R.A.; Chakrabarti, T.; Satpute, D.; Giri, B.S.; Mudliar, S. Evaluation of wet air oxidation as a pretreatment strategy for bioethanol production from rice husk and proces s optimization. Biomass Bioenergy 2009, 33, $1680-1686$. [CrossRef]

18. Li, Y.; Ding, X.F.; Guo, Y.P.; Rong, C.G.; Wang, L.L.; Qu, Y.N.; Ma, X.Y.; Wang, Z.C. A new method of comprehensive utilization of rice husk. J. Hazard. Mater. 2011, 186, 2151-2156. [CrossRef]

19. Carmona, V.B.; Oliveira, R.M.; Silva, W.T.L.; Mattoso, L.H.C.; Marconcini, J.M. Nanosilica from rice husk: Extraction and characterization. Ind. Crops Prod. 2013, 43, 291-296. [CrossRef]

20. Kim, S.J.; Kim, T.H.; Oh, K.K. Deacetylation Followed by Fractionation of Yellow Poplar Sawdust for the Production of ToxicityReduced Hemicellulosic Sugar for Ethanol Fermentation. Energies 2018, 11, 404. [CrossRef]

21. Santana Costa, J.A.; Paranhos, C.M. Systematic evaluation of amorphous silica production from rice husk ashes. J. Clean. Prod. 2018, 192, 688-697. [CrossRef]

22. Karera, A.; Nargis, S.; Patel, M. Silicon-based materials from rice husk. J. Sci. Ind. Res. 1986, 45, 441-448.

23. Walcarius, A. Silica-based electrochemical sensors and biosensors: Recent trends. Curr. Opin. Electrochem. 2018, 10, 88-97. [CrossRef]

24. Bharti, C.; Nagaich, U.; Pal, A.K.; Gulati, N. Mesoporous silica nanoparticles in target drug delivery system. Int. J. Pharm. Investig. 2015, 5, 124-133. [CrossRef] [PubMed]

25. Burakov, A.E.; Galunin, E.V.; Burakova, I.V.; Kucherova, A.E.; Agarwal, S.; Tkachev, A.G.; Gupta, V.K. Adsorption of heavy metals on conventional and nanostructured materials for wastewater treatment purposes. Ecotoxicol. Environ. Saf. 2018, 148, 702-712. [CrossRef] [PubMed]

26. Xu, L.; Zhu, D.; Lu, X.; Lu, Q. Transparent, thermally and mechanically stable superhydrophobic coating prepared by an electrochemical template strategy. J. Mater. Chem. A. 2015, 3, 3801-3807. [CrossRef]

27. Mebert, A.M.; Baglole, C.J.; Desimone, M.F.; Maysinger, D. Nanoengineered silica: Properties, applications and toxicity. Food Chem. Toxicol. 2017, 109, 753-770. [CrossRef]

28. Fernandes, I.J.; Calheiro, D.; Sanchez, F.A.L.; Camacho, A.L.D.; de Rocha, T.L.A.C.; Moraes, C.A.M.; de Sousa, V.C. Characterization of silica produced from rice husk ash: Comparison of purification and processing methods. Mater. Res. 2017, 20, 512-518. [CrossRef]

29. Habibi, Y. Key advances in the chemical modification of nanocelluloses. Chem. Soc. Rev. 2014, 43, 1519-1542. [CrossRef]

30. Zhu, G.; Lin, N. Surface Chemistry of Nanocellulose. In Nanocellulose: From Fundamentals to Advanced Materials; Wiley-VCH Verlag GmbH \& Co: Weinheim, Germany, 2019; pp. 115-153.

31. Klemm, D.; Heublein, B.; Fink, H.P.; Bohn, A. Cellulose: Fascinating biopolymer and sustainable raw material. Angew. Chem. Int. Ed. 2005, 44, 3358-3393. [CrossRef] [PubMed]

32. Moon, R.J.; Martini, A.; Nairn, J.; Simonsen, J.; Youngblood, J. Cellulosenanomaterials review: Structure, properties and nanocomposites. Chem. Soc.Rev. 2011, 40, 3941-3994. [CrossRef] [PubMed]

33. Lavoine, N.; Desloges, I.; Dufresne, A.; Bras, J. Microfibrillated cellulose-itsbarrier properties and applications in cellulosic materials: A review. Carbohydr. Polym. 2012, 90, 735-764. [CrossRef] [PubMed]

34. Isogai, A. Wood nanocelluloses: Fundamentals and applications as newbio-based nanomaterials. J. Wood Sci. 2013, 59, 449-459. [CrossRef]

35. Osong, S.H.; Norgren, S.; Engstrand, P. Processing of wood-basedmicrofibrillated cellulose and nanofibrillated cellulose, and applications relating to papermaking: A review. Cellulose 2016, 23, 93-123. [CrossRef]

36. Chauve, G.; Bras, J. Industrial point of view of nanocellulose materials and their possible applications. In Handbook of Green Materials; World Scientific: Singapore, 2014; pp. 233-252. [CrossRef]

37. Kim, T.H.; Im, D.; Oh, K.K.; Kim, T.H. Effects of Organosolv Pretreatment Using Temperature-Controlled Bench-Scale Ball Milling on Enzymatic Saccharification of Miscanthus $\times$ giganteus. Energies 2018, 11, 2657. [CrossRef]

38. Lee, J.Y.; Ryu, H.J.; Oh, K.K. Acid-catalyzed hydrothermal severity on the fractionation of agricultural residues for xylose-rich hydrolyzates. Bioresour. Technol. 2013, 132, 84-90. [CrossRef]

39. Kim, D.Y.; Kim, Y.S.; Kim, T.H.; Oh, K.K. Two-stage, acetic acid-aqueous ammonia, fractionation of empty fruit bunches for increased lignocellulosic biomass utilization. Bioresour. Technol. 2016, 199, 121-127. [CrossRef]

40. Zhang, H.; Ding, X.; Chen, X.; Ma, Y.; Wang, Z.; Zhao, X. A new method of utilizing rice husk: Consecutively preparing d-xylose, organosolv lignin, ethanol and amorphous superfine silica. J. Hazard. Mater. 2015, 291, 65-73. [CrossRef]

41. Sluiter, A.; Hames, B.; Ruiz, R.; Scarlata, C.; Sluiter, J.; Templeton, D. Determination of Sugars, Byproducts, and Degradation Products in Liquid Fraction Process Samples; Laboratory Analytical Procedure (LAP) NREL/TP-510-42623; National Renewable Energy Laboratory: Golden, CO, USA, 2008.

42. Kim, S.J.; Um, B.H.; Im, D.J.; Lee, J.H.; Oh, K.K. Combined Ball Milling and Ethanol Organosolv Pretreatment to Improve the Enzymatic Digestibility of Three Types of Herbaceous Biomass. Energies 2018, 11, 2457. [CrossRef]

43. Kim, T.H.; Oh, K.K.; Ryu, H.J.; Lee, K.H.; Kim, T.H. Hydrolysis of hemicellulose from barley straw and enhanced enzymatic saccharification of cellulose using acidified zinc chloride. Renew. Energy 2014, 65, 56-63. [CrossRef]

44. Sindhu, R.; Kuttiraja, M.; Binod, P.; Sukumaran, R.K.; Pandey, A. Physicochemical characterization of alkali pretreated sugarcane tops and optimization of enzymatic saccharification using response surface methodology. Renew. Energy 2014, 62, 362-368. [CrossRef] 
45. Nikzad, M.; Movagharnejad, K.; Talebnia, F.; Aghaiy, Z.; Mighani, M. Modeling of alkali pretreatment of rice husk using response surface methodology and artificial neural network. Chem. Eng. Commun. 2015, 202, 728-738. [CrossRef]

46. Shahabazuddin, M.; Chandra, T.S.; Meena, S.; Sukumaran, R.K.; Shetty, N.P.; Mudliar, S.N. Thermal assisted alkaline pretreatment of rice husk for enhanced biomass deconstruction and enzymatic saccharification: Physico-chemical and structural characterization. Bioresour. Technol. 2018, 263, 199-206. [CrossRef] [PubMed]

47. Schlomach, J.; Kind, M. Investigations on the semi-batch precipitation of silica. J. Colloid Interface Sci. 2004, 277, 316-326. [CrossRef] [PubMed]

48. Kracek, F.C. The system sodium oxide-silica. J. Phys. Chem. 2002, 34, 1583-1598. [CrossRef]

49. Sun, J.; Simon, S.L. The melting behavior of aluminum nanoparticles. Thermochim. Acta 2007, 463, 32-40. [CrossRef]

50. Lee, J.H.; Kwon, J.H.; Lee, J.W.; Lee, H.S.; Chang, J.H.; Sang, B.I. Preparation of high purity silica originated from rice husks by chemically removing metallic impurities. J. Ind. Eng. Chem. 2017, 50, 79-85. [CrossRef]

51. Azat, S.; Korobeinyk, A.V.; Moustakas, K.; Inglezakis, V.J. Sustainable production of pure silica from rice husk waste in Kazakhstan. J. Clean. Prod. 2019, 217, 352-359. [CrossRef]

52. Liu, Q.; Lu, Y.; Aguedo, M.; Jacquet, N.; Ouyang, C.; He, W.; Yan, C.; Bai, W.; Guo, R.; Goffin, D.; et al. Isolation of highpurity cellulose nanofibers from wheat straw through the combined environmentally friendly methods of steam explosion, microwave-assisted hydrolysis, and microfluidization. ACS Sustain. Chem. Eng. 2017, 5, 6183-6191. [CrossRef]

53. Rosa, S.M.L.; Rehman, N.; de Miranda, M.I.G.; Nachtigall, S.M.B.; Bica, C.I.D. Chlorine-free extraction of cellulose from rice husk and whisker isolation. Carbohydr. Polym. 2012, 87, 1131-1138. [CrossRef]

54. Chun, J.Y.; Gu, Y.M.; Hwang, J.K.; Oh, K.K.; Lee, J.H. Synthesis of ordered mesoporous silica with various pore structures using high-purity silica extracted from rice husk. J. Ind. Eng. Chem. 2020, 81, 135-143. [CrossRef]

55. Kaparaju, P.; Serrano, M.; Thomsen, A.B.; Kongjan, P.; Angelidaki, I. Bioethanol, biohydrogen and biogas production from wheat straw in a biorefinery concept. Bioresour. Technol. 2009, 100, 2562-2568. [CrossRef] [PubMed]

56. Choi, C.H.; Oh, K.K. Application of a continuous twin screw-driven process for dilute acid pretreatment of rape straw. Bioresour. Technol. 2012, 110, 349-354. [CrossRef] [PubMed]

57. Park, Y.C.; Kim, J.S. Comparison of various alkaline pretreatment methods of lignocellulosic biomass. Energy 2012, 47, 31-35. [CrossRef]

58. Stoklosa, R.J.; Hodge, D.B. Fractionation and improved enzymatic deconstruction of hardwoods with alkaline delignification. Bioenergy Res. 2015, 8, 1224-1234. [CrossRef]

59. Singh, D.P.; Trivedi, R.K. Acid and alkaline pretreatment of lignocellulosic biomass to produce ethanol as biofuel. Int. J. Chem. Tech. Res. 2013, 5, 727-734.

60. Park, B.; Wi, S.; Lee, K.; Singh, A.; Yoon, T.; Kim, Y. Characterization of anatomical features and silica distribution in rice husk using microscopic and micro-analytical techniques. Biomass Bioenergy 2003, 25, 319-327. [CrossRef]

61. Nechyporchuk, O.; Belgacem, M.N.; Bras, J. Production of cellulose nanofibrils: A review of recent advances. Ind. Crops Prod. 2016, 93, 2-25. [CrossRef] 